Article

\title{
Non-Enzymatic Glucose Sensor Composed of Carbon-Coated Nano-Zinc Oxide
}

\author{
Ren-Jei Chung ${ }^{1, *}$, An-Ni Wang ${ }^{1}$, Qing-Liang Liao ${ }^{2}$ and Kai-Yu Chuang ${ }^{1}$ \\ 1 Department of Chemical Engineering and Biotechnology, National Taipei University of Technology \\ (Taipei Tech), Taipei 10608, Taiwan; dai20020223@gmail.com (A.-N.W.); spa11012@hotmail.com (K.-Y.C.) \\ 2 Department of Materials Physics, State Key Laboratory for Advanced Metals and Materials, \\ University of Science and Technology Beijing, Beijing 100083, China; liao@ustb.edu.cn \\ * Correspondence: rjchung@ntut.edu.tw; Tel.: +886-287-728-701
}

Academic Editors: Hao-chung Kuo, Chien-chung Lin and Kai Wang

Received: 5 January 2017; Accepted: 7 February 2017; Published: 10 February 2017

\begin{abstract}
Nowadays glucose detection is of great importance in the fields of biological, environmental, and clinical analyzes. In this research, we report a zinc oxide $(\mathrm{ZnO})$ nanorod powder surface-coated with carbon material for non-enzymatic glucose sensor applications through a hydrothermal process and chemical vapor deposition method. A series of tests, including crystallinity analysis, microstructure observation, and electrochemical property investigations were carried out. For the cyclic voltammetric (CV) glucose detection, the low detection limit of $1 \mathrm{mM}$ with a linear range from $0.1 \mathrm{mM}$ to $10 \mathrm{mM}$ was attained. The sensitivity was $2.97 \mu \mathrm{A} / \mathrm{cm}^{2} \mathrm{mM}$, which is the most optimized ever reported. With such good analytical performance from a simple process, it is believed that the nanocomposites composed of $\mathrm{ZnO}$ nanorod powder surface-coated with carbon material are promising for the development of cost-effective non-enzymatic electrochemical glucose biosensors with high sensitivity.
\end{abstract}

Keywords: zinc oxide nanorod; carbon material; glucose; non-enzymatic electrochemical biosensor

\section{Introduction}

In recent years, biosensors have been investigated and applied in new drug discovery, clinical diagnosis, and forensic science. The goal is to minimize the size of detection instrument, detection sample, and detection period. The development of biosensors has become prevailingly studied topic in the biomedical field. In order to achieve specific detection, hybrid biosensors surface-modified with enzymes have been developed, called enzymatic sensors [1]. However, enzymatic sensors have drawbacks, including high cost, complicated production procedures, and short shelf lives, facing challenges in market. Additionally, an enzymatic sensor is impossible to implant into the human body for the long term and in situ monitoring due to the immobilized enzyme would degrade quickly [2]. In order to overcome this limitation, researchers place high expectations on non-enzymatic sensors; nevertheless, there are several critical issues, such as stability, selectivity, sensitivity, and detection limit [3-5].

Zinc oxide $(\mathrm{ZnO})$ is a II-VI semiconductor with a wide direct band gap $(3.37 \mathrm{eV})$ and electron binding energy $(60 \mathrm{meV})$. Different nano-structures of $\mathrm{ZnO}$ can be controlled through various preparation processes to acquire the desired physical properties, such as vapor-liquid-solid (VLS), chemical vapor deposition (CVD), hydrothermal processes, solution-liquid-solid (SLS), and capping agents/surfactant-assisted synthesis [6-9]. In the past 20 years, the $\mathrm{ZnO}$ nanostructure-based sensors have seen growing importance placed on research of various sensor techniques from chemical and biosensors, to UV and $\mathrm{pH}$ sensors [10-15]. In this study, we focused on glucose biosensors because of the upstream health issue on diabetes [16-18]. For glucose sensing, enzymatic and non-enzymatic $\mathrm{ZnO}$ glucose sensors are commonly reported [19-28]. Here, we have summarized some of the latest and important studies in Table 1 and the sensing performances are listed. 
Due to the $\mathrm{pH}$-sensitive glucose oxidase, most of the studies were performed in a neutral buffer solution ( $\mathrm{pH}$ 6.5-7.5) and cannot be used in severe $\mathrm{pH}$ conditions. The enzymatic sensors usually possess low detection limits and excellent sensitivity; however, the linear detection range is below human blood glucose concentration, ranging from 4 to $6 \mathrm{mM}$. Nevertheless, the linear range can be extended by decorating $\mathrm{ZnO}$ with carbon material to enhance the electron conductivity, surface area, and biocompatibility [20,22]. High conductivity could play an important role in the direct electrochemistry. Generally, the non-enzymatic sensors show higher detection limits than the enzymatic ones. A large linear range and an excellent sensitivity are two great benefits for rapid and direct detection in blood samples. In this study, we propose carbon-coated $\mathrm{ZnO}$ to enhance the performance for direct glucose sensing. We prepared zinc oxide $(\mathrm{ZnO})$ nanorod powder through a hydrothermal process, and then used a chemical vapor deposition method to surface-coat with carbon [29,30]. The $\mathrm{ZnO}$ and carbon-coated $\mathrm{ZnO}$ were immobilized onto a glassy carbon electrode to form non-enzymatic glucose sensors for comparison. Detailed investigations were then carried out.

Table 1. Important performance of enzymatic and non-enzymatic glucose sensors are summarized.

\begin{tabular}{|c|c|c|c|c|}
\hline Sensor & $\begin{array}{l}\text { Detect Limit } \\
\quad(\mathrm{mM})\end{array}$ & $\begin{array}{l}\text { Linear Range } \\
\text { (mM) }\end{array}$ & $\begin{array}{c}\text { Sensitivity } \\
\left(\mu \mathrm{A} / \mathrm{cm}^{2} \mathrm{mM}\right)\end{array}$ & Reference \\
\hline \multicolumn{5}{|c|}{ Enzymatic Glucose Sensor } \\
\hline GOx/C@ZnO nanowire/Ti & $10^{-3}$ & $0.01-16$ & 35.3 & Liu et al. 2009 [20] \\
\hline $\mathrm{GO} x / \mathrm{ZnO}$ & $5.6 \times 10^{-3}$ & Not mentioned & 21 & Ren et al. 2009 [21] \\
\hline $\mathrm{GO} x / \mathrm{ZnO}$ nanoparticle/IL/ESM & $10^{-10}$ & $10^{-9}-600$ & Not mentioned & Noor et al. 2015 [24] \\
\hline $\mathrm{GO} x / \mathrm{Pt}-\mathrm{Pb} / \mathrm{CNTs}$ & $10^{-3}$ & Up to 11 & 17.8 & Cui et al. 2007 [25] \\
\hline $\mathrm{GO} x / \mathrm{Cu} / \mathrm{MWCNTs}$ & $2.1 \times 10^{-4}$ & $0.7-3.5$ & 251.4 & Kang et al. 2007 [26] \\
\hline \multicolumn{5}{|c|}{ Non-enzymatic glucose sensor } \\
\hline $\mathrm{ZnO}$ nanoparticle & Not mentioned & $1-10$ & 38.133 & Singh et al. 2012 [27] \\
\hline C@ZnO/GC & 1 & $1-13.8$ & 2.97 & This study \\
\hline
\end{tabular}

\section{Materials and Methods}

In order to prepare the $\mathrm{ZnO}$ nanorod powder, $50 \mathrm{~mL}$ of $0.01 \mathrm{M} \mathrm{Zn}\left(\mathrm{NO}_{3}\right)_{2}$ was added dropwise into $50 \mathrm{~mL} 1 \mathrm{M} \mathrm{NaOH}$ for $15 \mathrm{~min}$ under stirring, and then the solution was heated to $95{ }^{\circ} \mathrm{C}$ and maintained for two hours. The precipitated $\mathrm{ZnO}$ nanorod powder was then centrifuged, thoroughly washed, and dried. The $\mathrm{ZnO}$ nanorod powder was then prepared for carbon coating. Carbon coating was performed using chemical vapor deposition (Figure 1). The source of carbon was ethanol carried by argon with a $50 \mathrm{sccm}$ flow rate. The reaction was carried out at $550{ }^{\circ} \mathrm{C}$ for $1.5 \mathrm{~h}$. Prior to the cyclic voltammetric $(\mathrm{CV})$ analysis, the structure of the as-synthesized $\mathrm{ZnO}$ powder was characterized by $X$-ray diffraction and $\theta / 2 \theta$ scan ranged from $20^{\circ}$ to $70^{\circ}$, where the $\mathrm{ZnO}$ was identified according to joint committee on powder diffraction standards (JCPDS) card No. 36-1451. The structure of the carbon-coated ( $\mathrm{ZnO} @ \mathrm{C}$ ) and uncoated $\mathrm{ZnO}$ powders was observed from the scanning electron microscope (SEM) topographies, high-resolution transmission electron microscopy (HRTEM) images, and selected area electron diffraction (SAED) pattern. Raman spectroscopy was used to identify the carbon coating. 


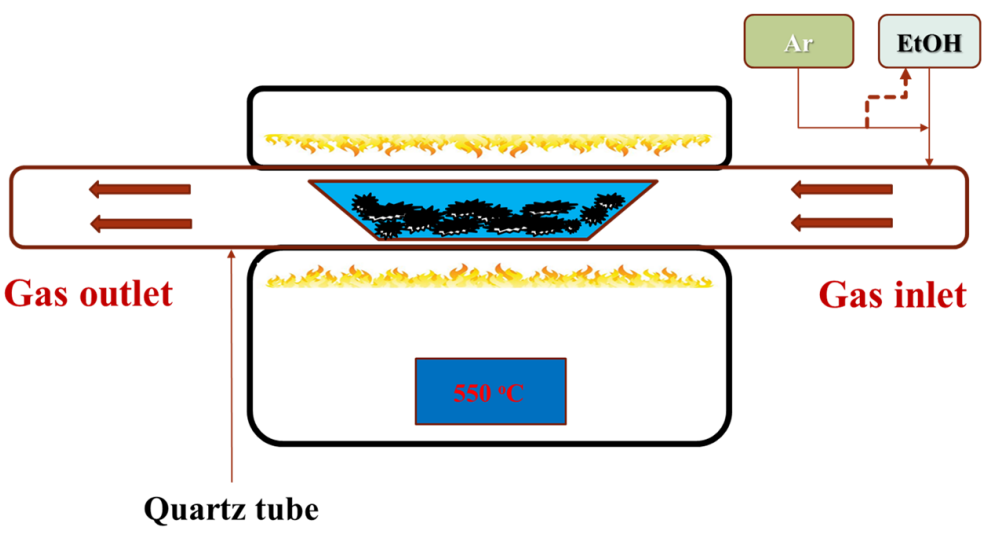

Figure 1. Scheme of the chemical vapor deposition (CVD) process.

The materials for sensor electrode were assembled on a $3 \mathrm{~mm}$ diameter glassy carbon working electrode (GC) (CHI104, CH Instrument, Inc., Austin, TX, USA). One milligram of carbon-coated $\mathrm{ZnO}(\mathrm{ZnO} @ \mathrm{C})$ nanorod powder was well mixed with $1 \mathrm{~mL}$ 5\% Nafion (Sigma-Aldrich, Shanghai, China) solution. Afterward, $1 \mathrm{~mL}$ of the mixed solution was transferred onto the glassy carbon (GC) electrode and dried at room temperature for $10 \mathrm{~min}$ to serve as a working electrode for $\mathrm{CV}$ glucose detection. In comparison with the $\mathrm{ZnO} @ \mathrm{C} / \mathrm{GC}$ electrode, $\mathrm{ZnO}$ on a glassy carbon electrode ( $\mathrm{ZnO} / \mathrm{GC})$ was carried out using the abovementioned method. Hence, three different working electrodes, including ZnO@C/GC, ZnO/GC and bare glassy carbon (GC), were used. As for the reference and the auxiliary electrodes, the commercial $\mathrm{Ag} / \mathrm{AgCl}$ reference electrode (RE-1B) and the platinum electrode were utilized, respectively. The CV scan was measured by utilizing a potentiostat CHI611E with a scanning range from $+1 \mathrm{~V}$ to $-1 \mathrm{~V}$. First, the $\mathrm{CV}$ profiles of the three different working electrodes were assessed in $1 \mathrm{M} \mathrm{NaOH}_{(\mathrm{aq})}$ solution $(\mathrm{pH}=12.5)$ and the similar solution with $1 \mathrm{mM}$ glucose to demonstrate the analytical performance of $\mathrm{ZnO}$ and $\mathrm{ZnO@C}$. To further investigate the $\mathrm{ZnO@C/GC}$ detector sensitivity and its limit, different scanning speeds from $10 \mathrm{mV} / \mathrm{s}$ to $100 \mathrm{mV} / \mathrm{s}, \mathrm{pH}$ values from 4 to 12.5 , and glucose concentrations from 0 to $11 \mathrm{mM}$ were used. Three standard buffer solutions were facilitated for $\mathrm{pH}=4,7$, and 10 , and $1 \mathrm{M} \mathrm{NaOH}_{(\mathrm{aq})}$ was utilized for $\mathrm{pH}=12.5$. Furthermore, the current vs. time curve of the $\mathrm{ZnO} @ \mathrm{C} / \mathrm{GC}$ electrode was measured at $0.38 \mathrm{~V}$ in $1 \mathrm{M} \mathrm{NaOH}_{(\mathrm{aq})}$ with respect to the glucose adding under a constant rate of $1 \mathrm{mM} / \mathrm{sec}$, ranging from 1 to $14 \mathrm{mM}$, from which the corresponding current vs. glucose concentration was plotted and calibrated. Last, the amperometric response of $\mathrm{ZnO} @ \mathrm{C} / \mathrm{GC}$ electrode to $1.0 \mathrm{mM}$ glucose as well as $1 \mathrm{mM}$ interferents of citric acid (CA), uric acid (UA), and dopamine (DA) was measured to investigate the specificity in glucose censing.

\section{Results and Discussion}

The X-ray diffraction (XRD) pattern of the as-synthesized $\mathrm{ZnO}$ powder is in Figure 2 and it is identical to the JCPDS card as shown in the bottom of the figure, indicating a hexagonal close packing (HCP) $\mathrm{ZnO}$ structure. From the interplanar spacing of all (hkl) directions, the lattice parameter of the $a$-axis and $c$-axis can be estimated by combining Bragg's law and the plane-spacing equation, and the resultant lattice parameters of $a$ - and $c$-axes are $3.22 \pm 0.02 \AA$ and $5.21 \pm 0.01 \AA$, respectively. Hence, the $c / a$ ratio is 1.62 , which is close to the ideal $\mathrm{ZnO}$ wurtzite structure $(c / a=1.633)$ [12]. The microstructures of the carbon-coated ( $\mathrm{ZnO} @ \mathrm{C}$ ) and uncoated $\mathrm{ZnO}$ nanoparticles were observed from the SEM image, as shown correspondingly in Figure $3 \mathrm{a}, \mathrm{b}$, in both of which $\mathrm{ZnO}$ nanorod structures can be found. Clearly, the carbon coating does not change the microstructure and only results in slightly larger $\mathrm{ZnO}$ particle size. 


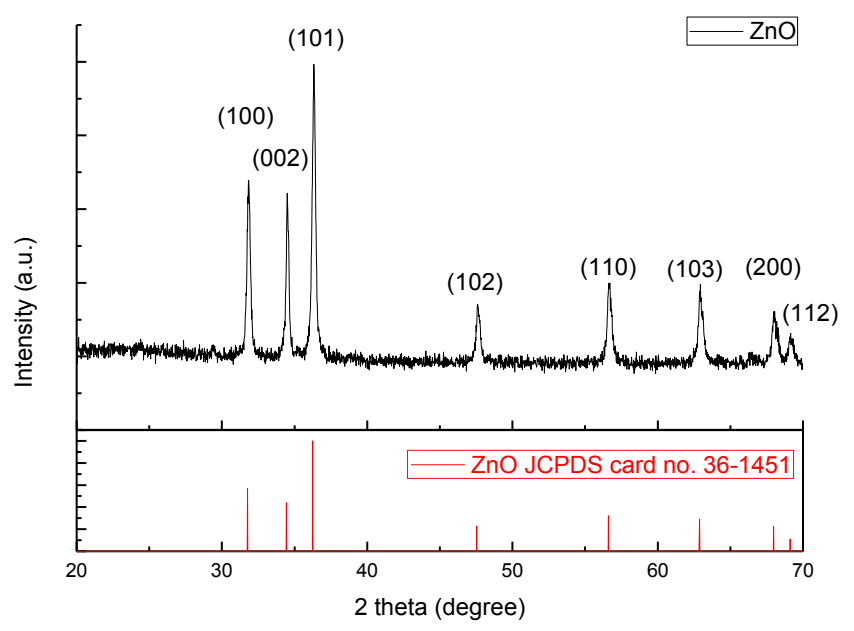

Figure 2. X-ray diffraction (XRD) pattern of the as-synthesized zinc oxide $(\mathrm{ZnO})$ nanorod powder.
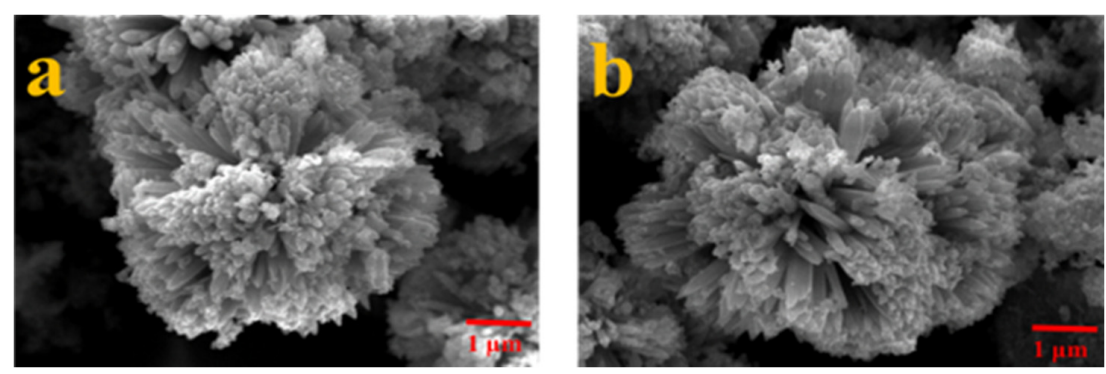

Figure 3. Micrographs of (a) $\mathrm{ZnO}$ and (b) $\mathrm{ZnO}$ (ZnO@C) nanorod powder.

A more detailed structural observation of the carbon coating was made by the TEM and HRTEM images, corresponding to Figure $4 \mathrm{a}, \mathrm{b}$. A thin and uniform carbon layer of $1 \mathrm{~nm}$ was observed on the $\mathrm{ZnO}$ nanorods; and a preferential growth of basal plane (0001) [0001] was found. In addition, the SAED pattern (Figure 4c) shows that the $\mathrm{ZnO}$ nanorods are close to a single crystal. To analyze the thin carbon layer on $\mathrm{ZnO}$, Raman spectroscopy was utilized and the comparison with uncoated $\mathrm{ZnO}$ is illustrated in Figure 5. The Raman spectrum of $\mathrm{ZnO}$ is labeled according to the B1, E2, and E1 vibration modes, where the E2 mode processing of $426 \mathrm{~cm}^{-1}$ was the most significant peak in both samples. A group of overlapping peaks corresponding to carbon D and G bands at $1340 \mathrm{~cm}^{-1}$ and $1588 \mathrm{~cm}^{-1}$ was observed. The intensity ratio $\left(I_{\mathrm{D}} / I_{\mathrm{G}}\right)$ was 0.98 , and this ratio corresponds to a tetrahedral amorphous carbon (ta-C) structure [31,32].

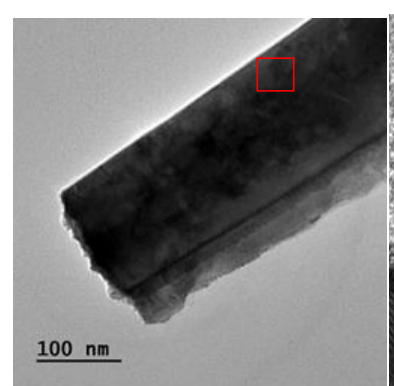

(a)

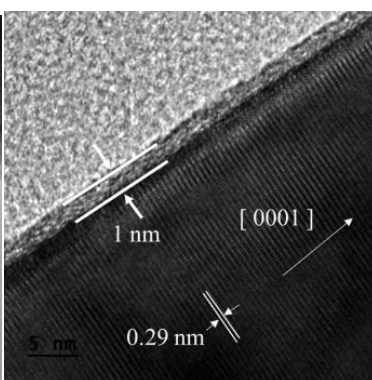

(b)

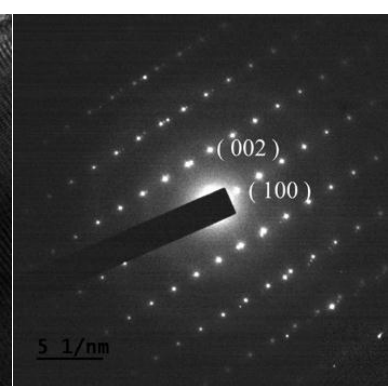

(c)

Figure 4. (a) Transmission electron microscopy (TEM) image; (b) high-resolution transmission electron microscopy (HRTEM) image; and (c) selected area electron diffraction (SAED) pattern of ZnO (ZnO@C) nanorod powder. 


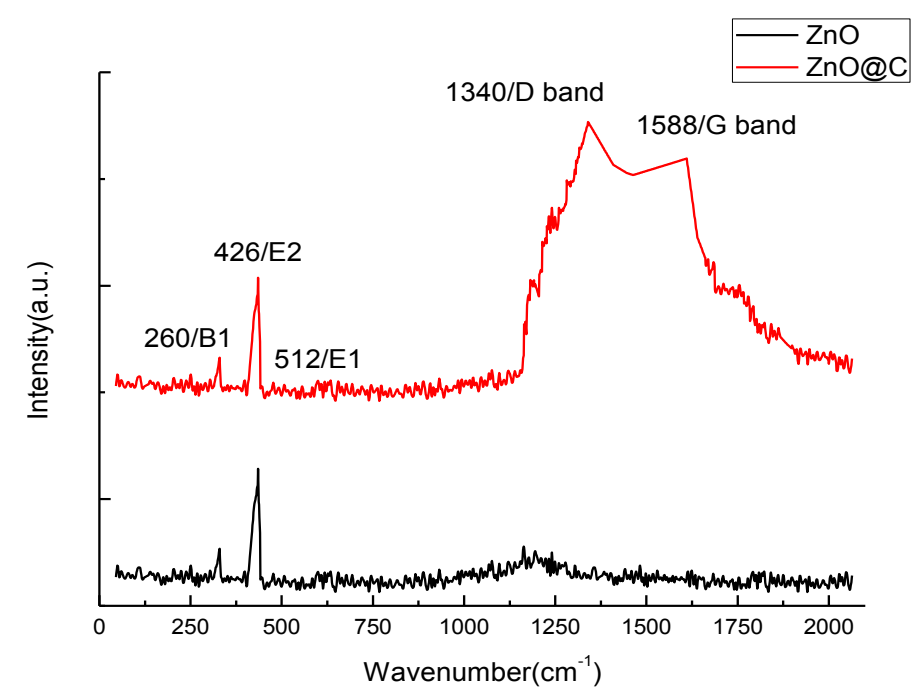

Figure 5. The Raman spectra of $\mathrm{ZnO}$ and carbon-coated $\mathrm{ZnO}$ nanorod powder. The Raman spectrum of $\mathrm{ZnO}$ was labeled according to the B1, E2, and E1 vibration modes, and those of carbon are D and G.

Figures 6 and 7 depict the $\mathrm{CV}$ of the analytical performances of $\mathrm{ZnO}$ and $\mathrm{ZnO} @ \mathrm{C}$ in $1 \mathrm{M} \mathrm{NaOH}_{(\mathrm{aq})}$ and $1 \mathrm{mM}$ glucose solutions, respectively. The ZnO@C electrode shows a great improvement of the sensitivity compared with the $\mathrm{ZnO} / \mathrm{GC}$ and GC electrode in both solutions, while the $\mathrm{ZnO} / \mathrm{GC}$ and GC electrode show similar CV curves in both situations. Evidently, the thin amorphous carbon layer $(1 \mathrm{~nm})$ is a key factor for the impressive improvement for sensing electrons and promoting the oxidation-redox reaction. Zhou et al. reported a similar $\mathrm{ZnO}$ nanowire or nanorod electrode for glucose sencing [28], for which the $\mathrm{ZnO}$ did not exhibit specific redox reaction with glucose. Without carbon decoration, $\mathrm{ZnO}$ does not react directly with glucose in the non-enzymatic detection. Hence, the role of $\mathrm{ZnO}$ in non-enzymatic sensors is inferred to accelerate the electron transfer. The carbon coating provides binding sites and electron transportation platforms for glucose.

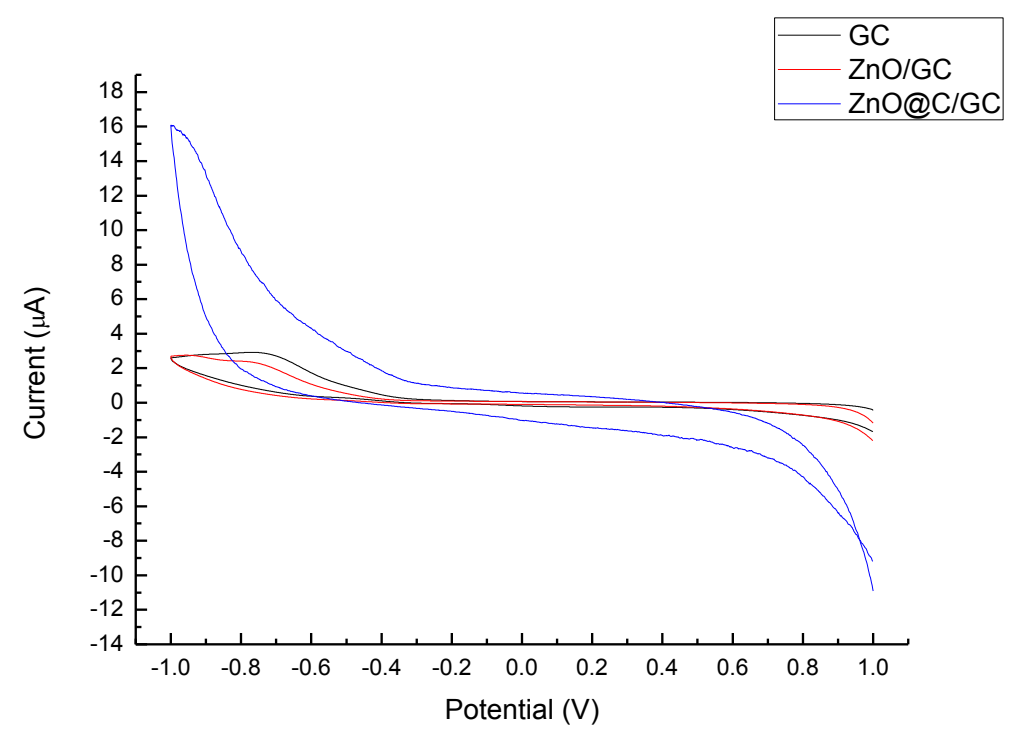

Figure 6. Cyclic voltammetric (CV) profiles of GC, ZnO/GC, and ZnO@C/GC electrodes in $1 \mathrm{M}$ $\mathrm{NaOH}_{(\mathrm{aq})}$ solution. 


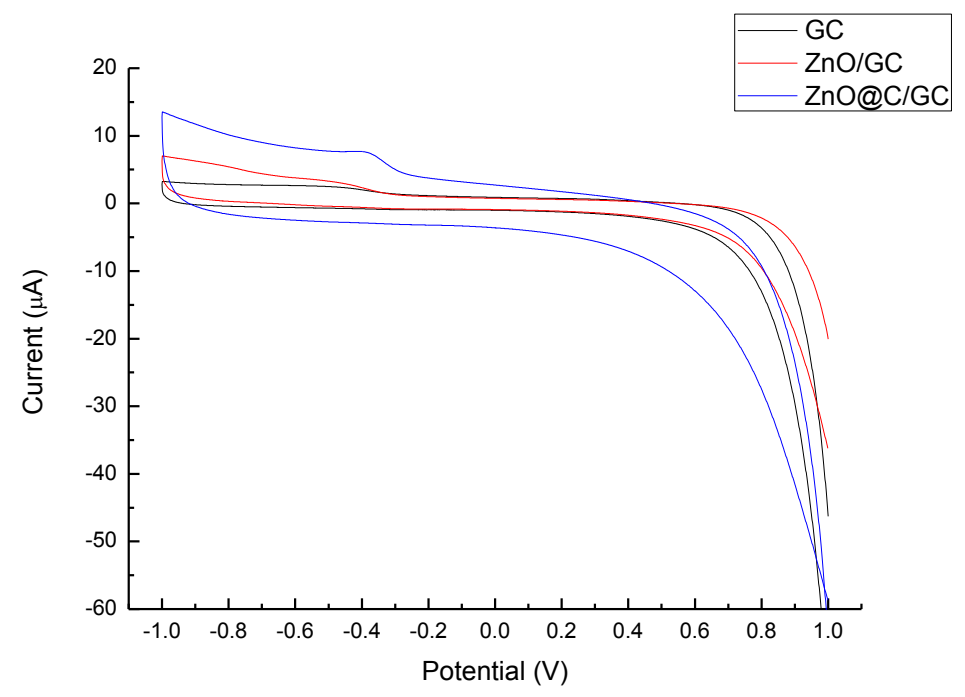

Figure 7. CV profiles of GC, ZnO/GC and ZnO@C/GC electrodes for $1 \mathrm{mM}$ glucose sensing.

In order to gain more understanding of the reaction and optimize the detection range, different scanning speeds (Figure 8) and $\mathrm{pH}$ values (Figure 9) were used on the CV scan of the $\mathrm{ZnO@C/GC}$ electrode. The symmetrical forward and backward current vs. the potential plots indicate that the redox reaction of glucose in $1 \mathrm{M} \mathrm{NaOH}_{(\mathrm{aq})}$ solution should be a reversible redox reaction. Moreover, the $\mathrm{I}_{\mathrm{PC}}$ increased as the scanning rate increased from $10 \mathrm{mV} / \mathrm{s}$ to $100 \mathrm{mV} / \mathrm{s}$, and the $\mathrm{I}_{\mathrm{PC}}$ was proportional to the square root of the scan speed following the Randles-Sevcilk equation. By comparing with the current range, the $\mathrm{pH}=12.5$ in $\mathrm{NaOH}_{(\mathrm{aq})}$ is much more sensitive than rest of the $\mathrm{pH}$ values; still, more complete $\mathrm{CV}$ plots are needed and will be further studied in the future. At $-0.4 \mathrm{~V}$, there was an additional peak from the enhanced redox reactions. The enhanced redox reaction was attributed to the great dependence of glucose oxidation on the influx of $\mathrm{OH}^{-}$[25]. The weakly bound hydrogen atom at glucose is the first to be detached on electrodes at low potentials. Hence, the influx of $\mathrm{OH}^{-}$ might enhance glucose oxidation by neutralizing protons generated during the dehydrogenation step. At $\mathrm{pH} 12.5$, the current of redox reactions became obvious, and the condition of $-0.4 \mathrm{~V}$, $\mathrm{pH} 12.5$, and a $100 \mathrm{mV} / \mathrm{s}$ scan rate was selected as the optimized detection situation. In brief, the optimized glucose detection using the $\mathrm{ZnO} @ \mathrm{C} / \mathrm{GC}$ electrode in this study is $\mathrm{pH}=12.5$ and a speed of $100 \mathrm{mV} / \mathrm{s}$. The asymmetry in the CV curves, attributed to three major mechanisms, including electron transportation between glucose and electrode, complicated kinetic control and diffusion control. Similar results were also reported in [24-26,28,30].

With the optimized conditions for CV glucose detection, we performed the glucose sensitivity test using various concentrations, adding at a rate of $1 \mathrm{mM}$ per $100 \mathrm{~s}$ (Figure 10). The current increased linearly with the increasing glucose concentration and the linear regression was calibrated in Figure 10b with the correlation factor of 0.99 . A perfect linear region can be found up to $10 \mathrm{mM}$, which is right in the range of human blood (4-6 mM). Since blood contains of lot of different chemicals, the amperometric response of the $\mathrm{ZnO} @ \mathrm{C} / \mathrm{GC}$ electrode was measured to investigate the specificity in glucose sensing (Figure 11). At $100 \mathrm{~s} 1 \mathrm{mM}$ glucose was added and the current increased significantly, then stabilized until the next interferent was added. The other three interferents (CA, UA, and DA) were added at a time interval of $100 \mathrm{~s}$, and the stabilized currents remained the same as the first glucose addition. In the last $100 \mathrm{~s}, 3 \mathrm{mM}$ glucose was added. The current responded similarly to the first glucose addition, but with an increasingly stabilized current (about 1.7 times), which is slightly smaller than in Figure 10 (about 2.2 times). The three interferents might influence the current value, but do not affect the specificity of the glucose sensing. However, the $\mathrm{pH}$ value of human blood is normally around 7 and this means that the blood sample requires some pre-treatment to increase the $\mathrm{pH}$ value. Still, the glucose concentration using $\mathrm{ZnO} @ \mathrm{C}$ can detect, linearly, up to $10 \mathrm{mM}$, meaning no dilution 
of the sample is needed and, thus, the accuracy will not be influenced. Therefore, the ZnO@C holds great potential for non-enzymatic glucose sensor applications. The sensitivity was calculated to be $2.97 \mu \mathrm{A} / \mathrm{cm}^{2} \mathrm{mM}$, as shown in Table 1, which is the most optimized ever reported.

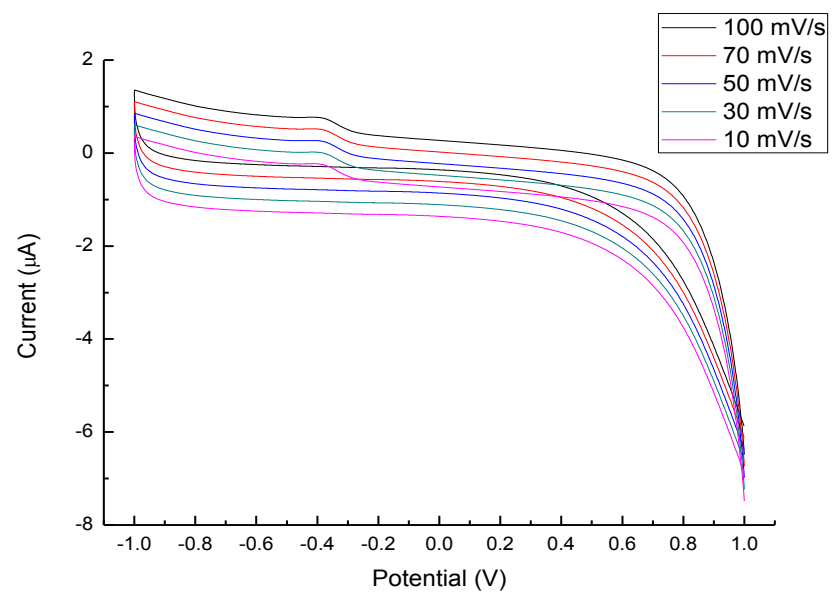

Figure 8. $\mathrm{CV}$ profiles under different scan rates in $1 \mathrm{M} \mathrm{NaOH}$ (aq) solution and $1 \mathrm{mM}$ glucose.

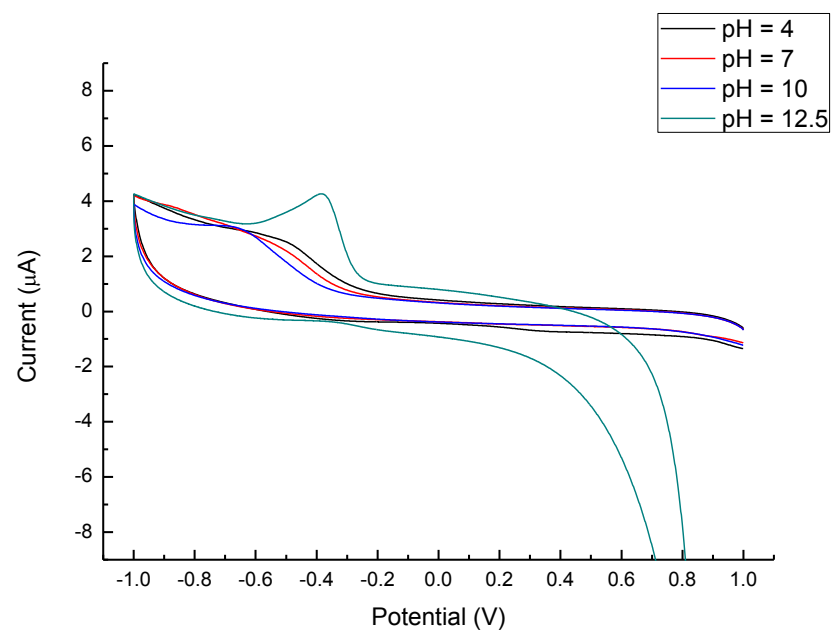

Figure 9. $\mathrm{CV}$ profile of $\mathrm{ZnO} @ \mathrm{C} / \mathrm{GC}$ electrodes under different $\mathrm{pH}$ values.

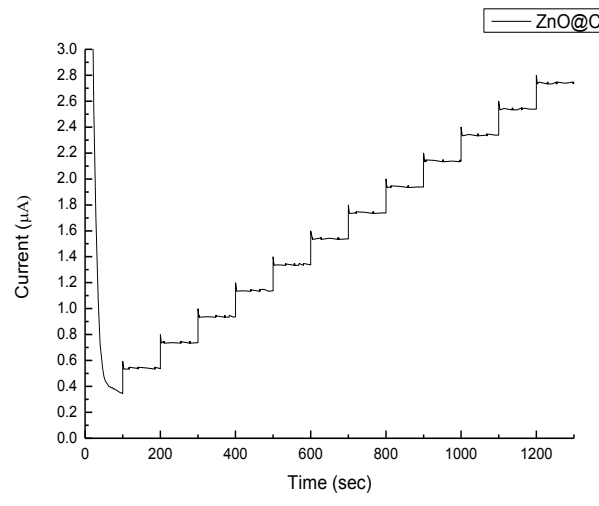

(a)

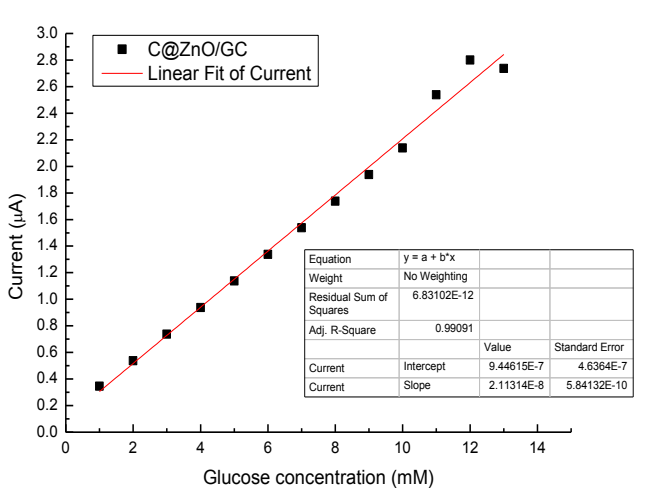

(b)

Figure 10. (a) The current vs. time curve of $\mathrm{ZnO} @ \mathrm{C} / \mathrm{GC}$ electrode in $1 \mathrm{M} \mathrm{NaOH}_{(\mathrm{aq})}$ and glucose $(\mathrm{aq})$ solution, where the glucose $(\mathrm{aq})$ was added $1 \mathrm{mM}$ per $100 \mathrm{~s}$; (b) The corresponding linear fitting of the stabilized current and glucose concentration from (a). 


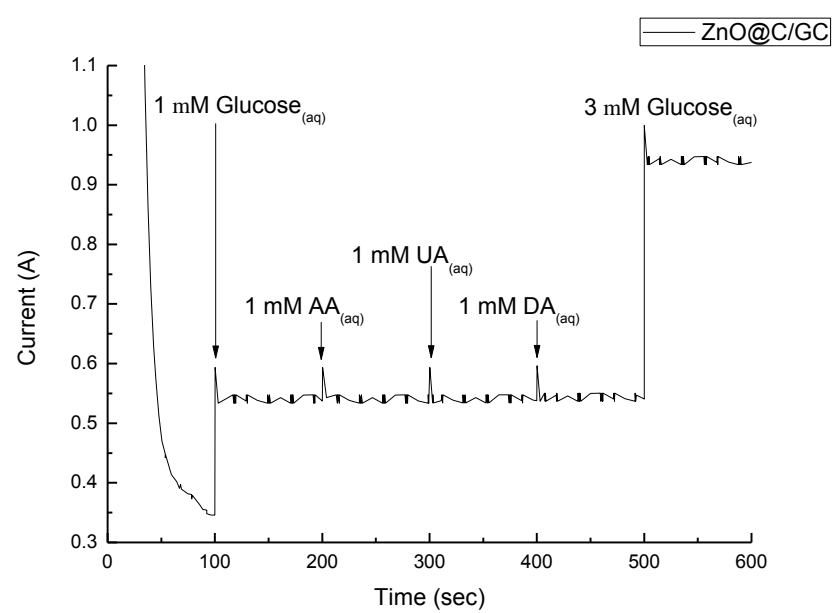

Figure 11. Amperometric response of $\mathrm{ZnO} @ \mathrm{C} / \mathrm{GC}$ electrode to $1.0 \mu \mathrm{M}$ glucose, as well as $1 \mathrm{mM}$ interferents of citric acid (CA), uric acid (UA), and dopamine (DA).

\section{Conclusions}

In this study, we investigated a carbon-coated zinc oxide (ZnO@C) nanorod material for non-enzymatic glucose censing via a combination of hydrothermal synthesis and chemical vapor deposition. A series of tests, including crystallinity analysis, microstructure observation, and electrochemical property investigations, were carried out. The thin amorphous carbon layer $(1 \mathrm{~nm})$ is a key factor for the impressive improvement for sensing electrons and promoting the redox reaction. For cyclic voltammetric (CV) glucose detection, the optimized conditions for the proposed material are $\mathrm{pH}=12.5$ and a speed of $100 \mathrm{mV} / \mathrm{s}$. Excellent analytical performance from the simple process include a low detection limit of $1 \mathrm{mM}$ and a linear range from $1 \mathrm{mM}$ to $13.8 \mathrm{mM}$. The $\mathrm{ZnO}$ nanorod powder surface-coated with carbon material is promising for the development of cost-effective non-enzymatic electrochemical glucose biosensors with high sensitivity.

Acknowledgments: The authors are grateful for the partial sponsorship of this research by the Ministry of Science and Technology of the Republic of China, under Grant No. MOST 103-2221-E-027-027 and MOST 104-2221-E-027-061; and partial sponsorship from the National Taipei University of Technology-University of Science and Technology Beijing Joint Research Program, under grant No. NTUT-USTB-103-01. The first, second, and third authors contributed equally to this work.

Author Contributions: Ren-Jei Chung organized and supervised this work; An-Ni Wang wrote the article and analyzed part of the data; Qing-Liang Liao supported and analyzed part of the data; Kai-Yu Chuang performed the experiments, measurements, and data analyses.

Conflicts of Interest: The authors declare no conflicts of interest.

\section{References}

1. Banica, F.G. Chemical Sensors and Biosensors: Fundamentals and Applications; John Wiley \& Sons: New York, NY, USA, 2012; pp. 3-13.

2. Toghill, E.K.; Richard, G.C. Electrochemical non-enzymatic glucose sensors: A perspective and an evaluation. Int. J. Electrochem. Sci. 2010, 5, 1246-1301.

3. Yogeswaran, U.; Chen, S.M. A review on the electrochemical sensors and biosensors composed of nanowires as sensing material. Sensors 2008, 8, 290-313. [CrossRef] [PubMed]

4. Chung, R.J.; Wang, H.Y.; Li, Y.C.; Yeh, P.H. Preparation and sensor application of carbon coated zinc oxide nanorods array. J. Aust. Ceram. Soc. 2013, 49, 81-88.

5. Kavitha, T.; Gopalan, A.I.; Lee, K.P.; Park, S.Y. Glucose sensing, photocatalytic and antibacterial properties of graphene-ZnO nanoparticle hybrids. Carbon 2012, 50, 2994-3000. [CrossRef]

6. Venditti, I.; Barbero, N.; Russo, M.V.; Carlo, A.D.; Decker, F.; Fratoddi, I.; Barolo, C.; Dini, D. Electrodeposited ZnO with squaraine sentisizers as photoactive anode of DSCs. Mater. Res. Exp. 2014, 1, 015040. [CrossRef] 
7. Carmona-Ribeiro, A.M. Biomimetic nanoparticles: Preparation, characterization and biomedical applications. Int. J. Nanomed. 2010, 5, 249-259. [CrossRef]

8. $\quad$ Chung, R.J.; Lin, Z.C.; Yang, P.K.; Lai, K.Y.; Jen, S.F.; Chiu, P.W. Hybrid ZnO NR/graphene structures as advanced optoelectronic devices with high transmittance. Nanoscale Res. Lett. 2013, 8, 350. [CrossRef] [PubMed]

9. Comini, E.; Sberveglieri, G. Metal oxide nanowires as chemical sensors. Mater. Today 2010, 13, 36-44. [CrossRef]

10. Segev-Bar, M.; Haick, H. Flexible sensors based on nanoparticles. ACS Nano 2013, 7, 8366-8378. [CrossRef] [PubMed]

11. Hajry, A.A.; Umar, A.; Hahn, Y.B.; Kim, D.H. Growth, properties and dye-sensitized solar cells-applications of $\mathrm{ZnO}$ nanorods grown by low-temperture solution process. Superlattice Microst. 2009, 45, 529-534. [CrossRef]

12. Wei, A.; Pan, L.H.; Huang, W. Recent progress in the ZnO nanostructure-based sensors. Mater. Sci. Eng. B 2011, 176, 1409-1421. [CrossRef]

13. Bearzotti, A.; Macagnano, A.; Pantalei, S.; Zampetti, E.; Venditti, I.; Fratoddi, I.; Russo, M.V. Alcohol vapors sensory properties of nanostructured conjugated polymer. J. Phys. Condens. Mat. 2008, 20, 474207. [CrossRef]

14. Fratoddi, I.; Bearzotti, A.; Venditti, I.; Cametti, C.; Russo, M.V. Role of nanostructured polymers on the improvement of electrical response-based relative humidity sensors. Sens. Actuators B Chem. 2016, 225, 96-108. [CrossRef]

15. He, J.H.; Ho, C.H.; Chen, C.Y. Polymer functionalized $\mathrm{ZnO}$ nanobelt as oxygen sensors with a significant response enhancement. Nanotechnology 2009, 20, 065503. [CrossRef] [PubMed]

16. Hsu, Y.W.; Hsu, T.K.; Sun, C.L.; Nien, Y.T.; Pu, N.W.; Ger, M.D. Synthesis of CuO/graphene nanocomposites for nonenzymatic electrochemical glucose biosensor applications. Electrochim. Acta 2012, 8, 152-157. [CrossRef]

17. Wu, J.; Yin, F. Easy fabrication of a sensitive non-enzymatic glucose sensor based on electrospinning CuO-ZnO nanocomposites. Integr. Ferroelectr. 2013, 147, 47-58. [CrossRef]

18. Yoon, S.S.; Ramadoss, A.; Saravanakumar, B.; Kim, S.J. Novel Cu/CuO/ZnO hybrid hierarchical nanostructures for non-enzymatic glucose sensor application. J. Electroanal. Chem. 2014, 717-718, 90-95.

19. Wei, A.; Sun, X.W.; Wang, J.X.; Lei, Y.; Cai, X.P.; Li, C.M.; Dong, Z.L.; Huang, W. Enzymatic glucose biosensor based on $\mathrm{ZnO}$ nanorod array grown by hydrothermal decomposition. Appl. Phys. Lett. 2006, 89, 123902. [CrossRef]

20. Liu, J.P.; Guo, C.X.; Li, C.M.; Li, Y.Y.; Chi, Q.B.; Huang, X.T.; Liao, L.; Yu, T. Carbon-decorated ZnO nanowire array: A novel platform for direct electrochemistry of enzymes and biosensing applications. Electrochem. Commun. 2009, 11, 202-205. [CrossRef]

21. Ren, X.L.; Chen, D.; Meng, X.W.; Tang, F.Q.; Hou, X.Q.; Han, D.; Zang, L. Zinc oxide nanoparticles/glucose oxidase photoelectrochemical system for the fabrication of biosensor. J. Colloid Inter. Sci. 2009, 334, 183-187. [CrossRef] [PubMed]

22. Hwa, K.Y.; Subramani, B. Synthesis of zinc oxide nanoparticles on graphene-carbon nanotube hybrid for glucose biosensor applications. Biosens. Bioelectron. 2014, 62, 127-133. [CrossRef] [PubMed]

23. Marie, M.; Mandal, S.; Manasreh, O. An electrochemical glucose sensor based on zinc oxide nanorods. Sensors 2015, 15, 18714-18723. [CrossRef] [PubMed]

24. Aini, B.N.; Siddiquee, S.; Ampon, K.; Rodrigues, K.F.; Suryani, S. Development of glucose biosensor based on $\mathrm{ZnO}$ nanoparticles film and glucose oxidase-immobilized eggshell membrane. Sens. Biosensing. Res. 2015, 4, 46-56. [CrossRef]

25. Cui, H.F.; Ye, J.S.; Zhang, W.D.; Li, C.M.; Luong, J.H.T.; Sheu, F.S. Selective and sensitive electro-chemical detection of glucose in neutral solution using platinum-lead alloy nanoparticle/carbon nanotube nanocomposites. Anal. Chim. Acta 2007, 594, 175-183. [CrossRef] [PubMed]

26. Kang, X.H.; Mai, Z.B.; Zou, X.Y.; Cai, P.X.; Mo, J.Y. A sensitive nonenzymatic glucose sensor in alkaline media with a copper nanocluster/multiwall carbon nano tube-modified glassy carbon electrode. Anal. Biochem. 2007, 363, 143-150. [CrossRef] [PubMed]

27. Singh, K.; Umar, A.; Kumar, A.; Chaudhary, G.R.; Singh, S.; Mehta, S.K. Non-enzymatic glucose sensor based on well-crystallized ZnO nanoparticles. Sci. Adv. Mater. 2012, 4, 994-1000. [CrossRef] 
28. Zhou, C.; Xu, L.; Song, J.; Xing, R.; Xu, S.; Liu, D.; Song, H. Ultrasensitive non-enzymatic glucose sensor based on three-dimensional network of $\mathrm{ZnO}-\mathrm{CuO}$ hierarchical nanocomposites by electrospinning. Sci. Rep. 2014, 4, 7382. [CrossRef]

29. Li, X.; Zhao, C.; Liu, X.Y. A paper-based microfluidic biosensor integrating zinc oxide nanowires for electrochemical glucose detection. Microsyst. Nanoeng. 2015, 1, 15014. [CrossRef]

30. Zhang, X.H.; Zhang, Z.; Liao, Q.L.; Liu, S.; Kang, Z.; Zhang, Y. Nonenzymatic glucose sensor based on in situ reduction of $\mathrm{Ni} / \mathrm{NiO}$-graphene nanocomposite. Sensors 2016, 16, 1791. [CrossRef] [PubMed]

31. Frackowiak, E. Carbon materials for supercapacitor application. Phys. Chem. Chem. Phys. 2007, 9, 1774-1785. [CrossRef] [PubMed]

32. Ferrari, A.C.; Robertson, J. Interpretation of Raman spectra of disordered and amorphous carbon. Phys. Rev. B 2000, 61, 14095-14107. [CrossRef]

(C) 2017 by the authors; licensee MDPI, Basel, Switzerland. This article is an open access article distributed under the terms and conditions of the Creative Commons Attribution (CC BY) license (http://creativecommons.org/licenses/by/4.0/). 